\title{
Assessment of the Efficiency of Wind Energy Use in Russia
}

\author{
Alexey Bataev ${ }^{*}$, Elena Eskina ${ }^{2}$ \\ ${ }^{1}$ Peter the Great St. Petersburg Polytechnic University, 195521 Polytechnicheskaya, 29, Saint- \\ Petersburg, Russia \\ ${ }^{2}$ Samara University, Moskovskoye shosse 34, Samara, 443086, Russia
}

\begin{abstract}
The constant increase in the requirements for the generation of electricity forces the search for new means of generating energy. It is not the first year that technologies for the development of alternative energy sources have been considered and introduced in the largest countries of the world. Wind power occupies a special place in this direction. In Russia, this industry is still not sufficiently developed to provide a significant share of energy consumption, but the industrial potential with the proper level of technological support can radically correct this situation. This article discusses the perspectives for using wind power plants in Russia. A mathematical model of a wind power plant was built in this study, taking into account the parameters of a WH6.4-5000W type wind generator and consisting of a virtual synchronous generator, which is an element of the SimPowerSystem library, and blocks from the Simulink application of the Matlab software package that simulates the effect of wind and the movement of the mechanical part of the wind generator. An assessment of the economic efficiency of the use of wind turbines in Russia was carried out using the constructed model.
\end{abstract}

\section{Introduction}

The volatility of oil prices and the challenge of improving energy security cause the rapid development of wind generators as one of the most efficient sources of alternative energy. According to various estimates, wind turbines with a total capacity of 150-170 GW operate all over the world, and this is about $1.5-2 \%$ of the total energy consumption in the world. However, we are talking about electricity, as the most acceptable form of energy for accumulation and transformation. Moreover, in some countries, this indicator is also growing at a very active pace. For example, wind farms in Denmark already provide more than $20 \%$ of the needs of electricity consumers, in Spain and Germany - at the level of $10 \%$. In Russia, the state and perspectives of wind energy are largely determined by government support and market incentives. But, unlike European states that are successfully mastering this method of energy generation, the domestic industry is noticeably lagging in terms of technology. At least this concern the directions of development of industrial energy based on alternative sources. $[1,2]$

\footnotetext{
*Corresponding author: bat_a68@mail.ru
} 
At the moment, several large-scale projects are being implemented, which should ensure the energy independence of certain regions in Chukotka, Bashkortostan, Karelia, etc. The existing stations mainly perform the functions of emergency power supply and are only rarely used as a way to optimize energy costs. The main assets of the wind energy complex in Russia include generator sets with a capacity of 0.1-2 MW. Multicomponent systems are especially popular that include several small generators of $250-550 \mathrm{~kW}$ each. On average, these capacities produce about 0.4 million $\mathrm{kWh}$ per year. [3]

The current state of wind energy in Russia and the proliferation of individual generators are characterized. These are small installations that are able to cover the energy requirements of private households - at the level of 1-5 kW. However, the popularization of low-power wind turbines also faces problems, most of which have financial difficulties in the design, installation and purchase of components; nevertheless, the use of wind turbines is a fairly promising direction, which is convincingly proven by the study.

\section{Results}

Let us conduct an assessment of the economic efficiency of a wind power plant using one of the most relevant and universal research methods - mathematical modeling.

We will design a model of a wind turbine that will take into account the parameters of the horizontal wind turbine WH6.4-5000W. [4]

The differential equation of motion of the wind turbine has the form:

$$
J \frac{d \omega}{d t}=M_{w}-M_{g}-k_{m p} \omega
$$

where $J$ - total moment of inertia reduced to the generator shaft, $\mathrm{kg} \cdot \mathrm{m}^{2}$

$M_{w}$ - wind turbine mechanical moment, $\mathrm{N} \cdot \mathrm{m}$

$M_{g}$ - generator electromagnetic moment, $\mathrm{N} \cdot \mathrm{m}$

$\omega-$ generator shaft speed, rad $\cdot \mathrm{s}$

Making the substitution $s=\frac{d}{d t}$, we write equation (1) in the operator form

$$
J s \omega=M_{w}-M_{g}-k_{m p} \omega
$$

A block diagram characterizing the workflow in an electrical installation is shown in Figure 1.

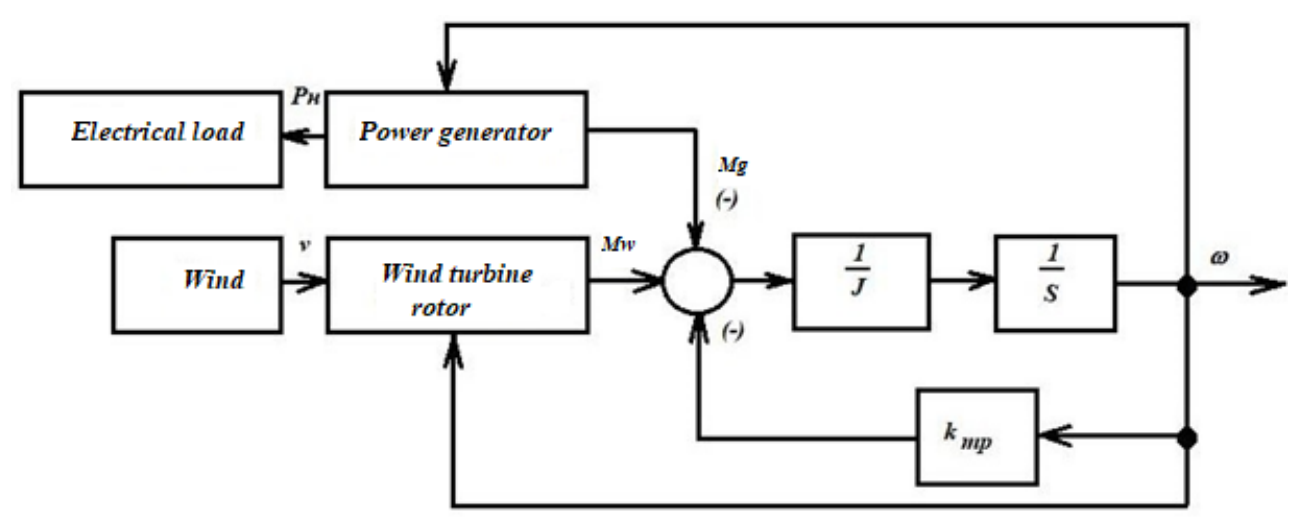

Fig. 1. Structural diagram of a wind power plant. 
Let us find the transfer function for the mechanical part of the wind generator:

$$
\frac{\omega(s)}{M_{r e s}}=\frac{1 J s}{1+k_{m p} \cdot 1 \mathrm{Js}}
$$

where $M_{\text {res }} S=M_{w}-M_{g}-$ the resulting torque on the generator shaft, created from the rotation of the wind wheel and the action of the electromagnetic moment of the synchronous generator.

We multiply the numerator and denominator of expression (3) by $J s$, we get the following expression:

$$
\frac{\omega(s)}{M_{\text {res }}}=\frac{1 J s}{1+k_{m p} \cdot 1 J s}=\frac{1}{J s+k_{m p}}
$$

We take out the coefficient in the denominator outside the bracket $k_{m p}$, we get the following expression for the transfer function $\frac{\omega(s)}{M_{\text {res }}}$.

$$
\frac{\omega(s)}{M_{\text {res }}}=\frac{1 k_{m p}}{T_{m e c h}+1}
$$

where $T_{m e c h}=\frac{J}{k_{m p}}-$ time constant of the mechanical part of the wind generator.

The introduced simplifications are reflected in the block diagram (Fig. 2).

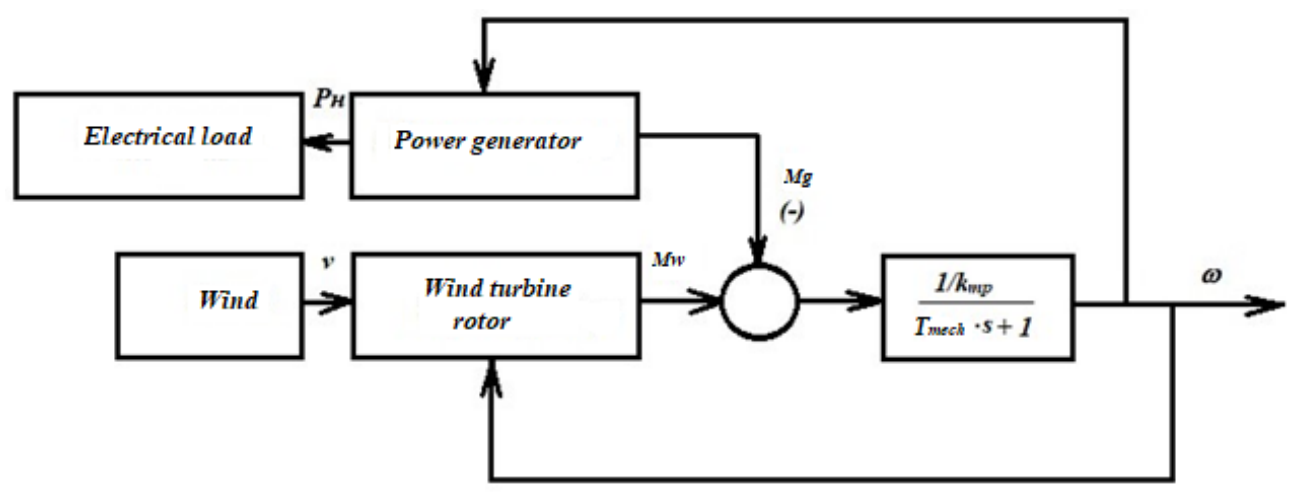

Fig. 2. Structural diagram of a wind power plant with simplification of the mechanical part.

The positive mechanical moment created by the wind wheel depends on its radius $(R)$, air density $(\rho)$ and wind speed $(v)$ :

$$
M_{w}=\frac{1}{2} \rho \pi R^{3} v^{2} C_{p}
$$

This formula includes the power factor of the wind wheel $C_{p}$, the value of which is nonlinearly related to such factors as speed $(\lambda)$ and the angle of attack of the blades $(\beta)$ $[5,6]$.

From the passport data of the wind generator, the following are known:

The power utilization factor is $C_{p}=0,4$;

Wind wheel radius is $R=3,2 \mathrm{~m}$; 
Rated speed of rotation is $\omega=25,12 \mathrm{rad} / \mathrm{s}(240 \mathrm{rpm})$;

Maximum wind speed is $v=20 \mathrm{~m} / \mathrm{s}$;

Air density is $\rho=1,25 \mathrm{~kg} / \mathrm{m}^{3}$.

By substituting these parameters into formula (3), we obtain the value of the motor torque on the generator shaft:

$$
M_{w}=24,69 \cdot v^{2} N \cdot m
$$

The total moment of inertia is equal to the sum of the moments of inertia of the generator shaft and the wind wheel. Since the diameter of the wind wheel significantly exceeds the diameter of the rotor of the electric generator, then in modeling we use only the value of the moment of inertia of the wind wheel.

$$
J=\frac{G \cdot D^{2}}{12}=\frac{2 \cdot 6,4^{2}}{12}=6,8 \mathrm{~kg} \cdot \mathrm{m}^{2}
$$

The coefficient of friction is $2-5 \%$ of the nominal power of the wind turbine, which is approximately equal to

$$
k_{m p} \approx 0,02 \cdot P_{\text {nom }}=0,038 \cdot 5
$$

The model will be created in the Simulink application of the Matlab program.

1) To simulate the wind, we use a generator of normally distributed random variables. The average value of the random sequence corresponds to the average annual wind speed on the territory of the plant $(6 \mathrm{~m} / \mathrm{s})$.

2) To simulate a generator and load, we use virtual blocks of these elements from the SimPawerSystem library.

Figure 3 shows the simulation results.

a)

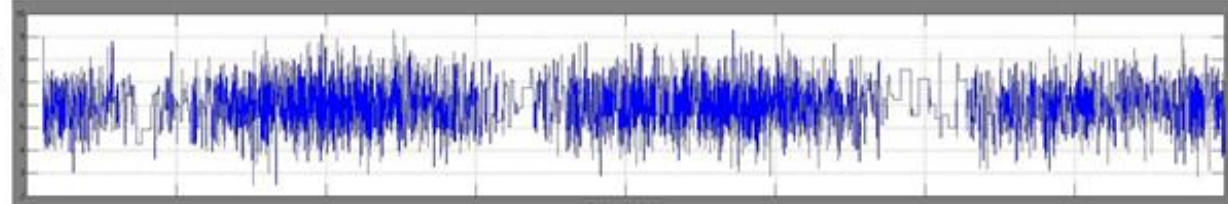

b)

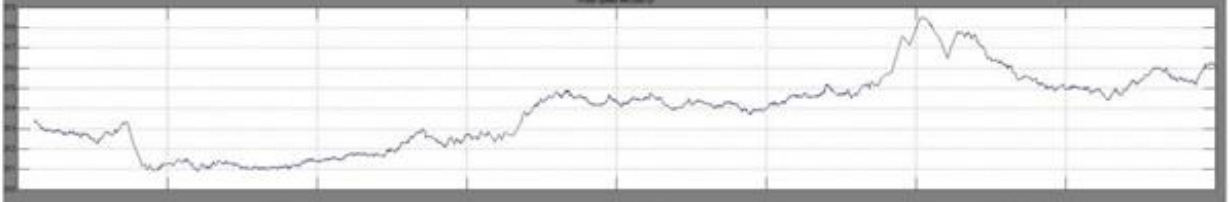

c)

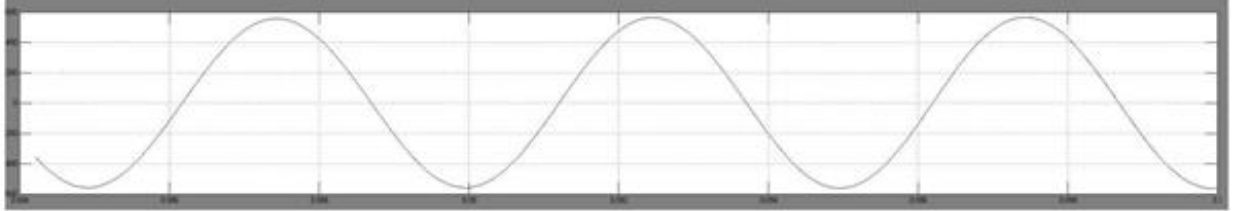

Fig. 3. Simulation results: a - wind speed, b - rotation speed of the synchronous generator shaft, c - generated voltage.

Figure 4 shows a diagram of the developed model.

In the given virtual diagram, the following structural parts are highlighted:

a - generator and load;

$\mathrm{b}$ - wind;

c - wind wheel; 
d - mechanical part.

As can be seen from the graphs, the rotation speed of the electric generator changes in accordance with the change in the wind speed. This result corresponds to reality, so this model can be used as a basis for solving more complex problems.

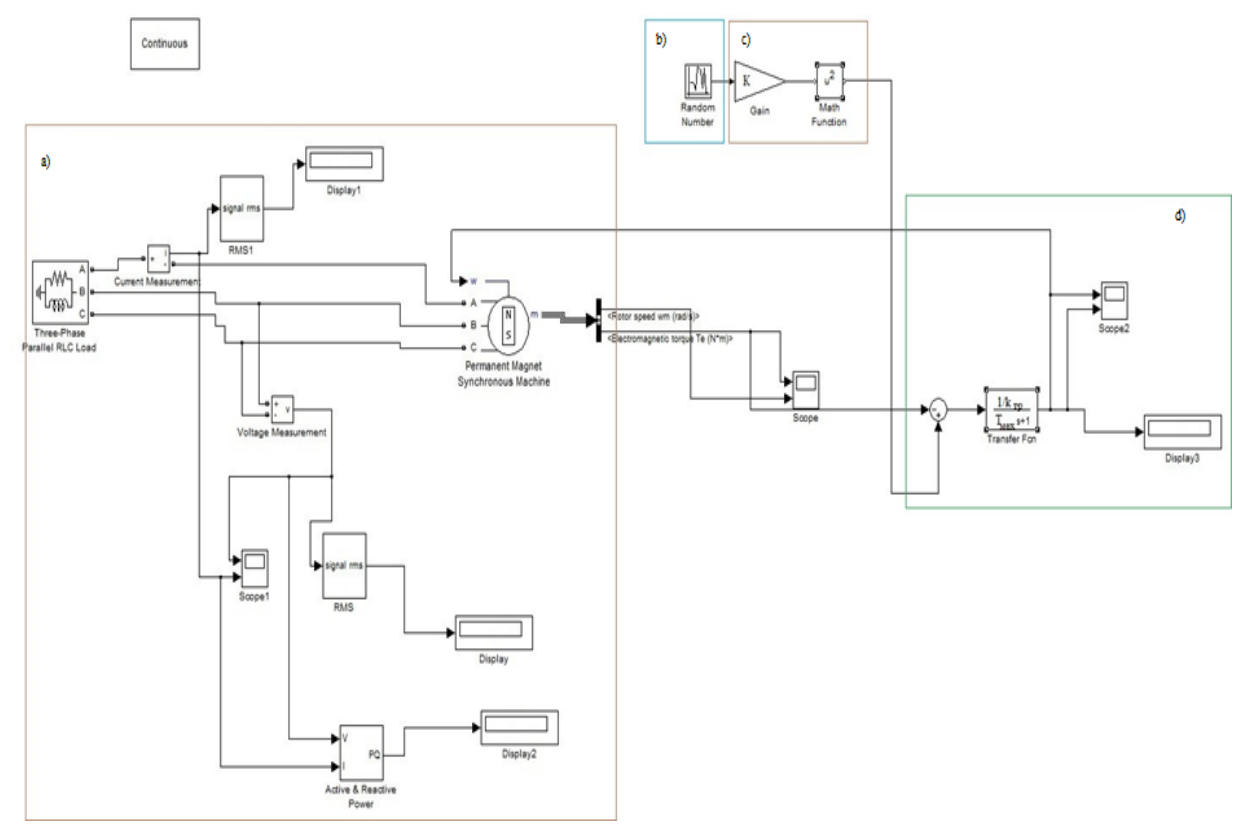

Fig. 4. Wind turbine model in Simulink application of Matlab program.

The main criteria for the technical and economic efficiency of wind power plants include the main factors [7-9]:

- annual expenses per $1 \mathrm{~kW}$ of installed capacity;

- cost of $1 \mathrm{~kW} \cdot \mathrm{h}$ of electricity.

These criteria are determined by the methodology and consist of the following expressions[10-13]:

$$
E=\frac{E_{N} K+C}{P}
$$

where $\mathrm{P}$ is the installed capacity of the power supply facility, $\mathrm{kW}$;

$\mathrm{K}$ is total capital investment, rubles.

$$
K=K_{c e}+K_{\text {des }}+K_{\text {constr }}
$$

where $K_{c e}$ - the cost of complete equipment, rubles;

$K_{\text {des }}$ - the cost of design work to determine the installation site on the ground, rubles;

$K_{\text {constr }}$ - the cost of construction and installation work for the installation of a wind farm, rubles;

$E_{N}=\frac{1}{T}$ - standard profitability ratio;

$\mathrm{T}$ - economic life of equipment, years.

$\mathrm{C}$ is total annual operating costs, rubles.

$$
C=C_{\text {oper }}+\mathrm{C}_{\text {rep }}
$$

where $C_{\text {oper }}$ - annual costs of operating the power supply system, rubles; 
$\mathrm{C}_{\text {rep }}$ - annual expenses for planned repairs, rubles.

The cost of $1 \cdot \mathrm{kWh}$ of electricity is calculated by the formula:

$$
C_{e l}=\frac{P_{n} K+C}{W},[r u b / k W h]
$$

$W$ - the total amount of electrical energy generated by the power plant per year.

Under the existing economic conditions in this area in Russia, the economic analysis of autonomous power supply can lead to a reduction in budget subsidies. Accordingly, the profitability of generating electricity in isolated power supply systems is not worth mentioning. The normal coefficient of profitability in such situations is advisable to choose based on the service life of the equipment.

The service life of the main equipment of the wind farm is $\mathrm{T}=20$ years, respectively, the standard profitability ratio is $E_{N}=0,05$.

To operate a wind farm, two specialists are needed with an average salary of 25,000 rubles per month, which will amount to 300,000 rubles.

The cost of current repairs can be taken at $1 \%$ of the cost of the equipment, which will amount to 19,168 rubles in a year.

The total amount of annual operating costs is calculated by the formula (9):

$$
\mathrm{C}=19168+300000=319168 \mathrm{rub} \text {. }
$$

Let us calculate the annual costs per $1 \mathrm{~kW}$ of installed capacity according to the formula (4.7):

$$
C=\frac{0,05 \cdot 2300112+319168}{15}=28945 \mathrm{rub} . / \mathrm{kW}
$$

The cost of electricity produced is calculated by the formula (4.10):

$$
C_{e l}=\frac{0,05 \cdot 2300112+319168}{33075}=13 \mathrm{rub} . / \mathrm{kWh}
$$

Next, we will calculate the energy savings in kind per year using the following formula:

$$
E_{s}=P \cdot n \cdot N_{h}
$$

where $E_{S}$ - energy savings in kind per year, $\mathrm{kW} \cdot \mathrm{h}$;

$P$ - installed capacity of equipment, $\mathrm{kW}$;

$n$ - number of electrical equipment;

$N_{h}$ - the average operating hours of a wind turbine per year is defined as the product of the number of days of operation of a wind turbine per year by the number of hours of operation per day (315 days 7 hours a day).

$E_{s}=15 \cdot 9 \cdot 2205=297675 \mathrm{~kW} \cdot \mathrm{h}$

In terms of fuel equivalent, the annual savings will be:

$$
E_{\text {st.u.t. }}=297675 \cdot 0,3=89302,5 \text { t.u.t. }
$$

Table 1. Economic characteristics of a wind turbine.

\begin{tabular}{|c|c|c|c|}
\hline Name of devices & Quantity, pes. & $\begin{array}{c}\text { Price per piece, } \\
\text { rubles }\end{array}$ & Amount, rubles \\
\hline $\begin{array}{c}\text { Wind generator WH6.4-5000W } \\
\text { https://tiu.ru/p34520148- }\end{array}$ & & & \\
\hline
\end{tabular}




\begin{tabular}{|c|c|c|c|}
\hline Name of devices & Quantity, pes. & $\begin{array}{c}\text { Price per piece, } \\
\text { rubles }\end{array}$ & Amount, rubles \\
\hline $\begin{array}{c}\text { vetrogenerator-wh64- } \\
\text { 5000.html }\end{array}$ & 2 & 689790 & 1379580 \\
\hline Mast 12 m & 2 & 78600 & 157200 \\
\hline $\begin{array}{c}\text { Inverter MAC SIN HYBRID } \\
\text { 48V 20kW } \\
\text { Micro Art }\end{array}$ & 1 & 195900 & 195900 \\
\hline $\begin{array}{c}\text { Rechargeable battery VOLTA } \\
\text { ST 12 - 200 200 A.h 12V }\end{array}$ & 6 & 30680 & 184080 \\
\hline Total equipment & & 383352 \\
\hline $\begin{array}{c}\text { Construction and installation } \\
\text { works (20\% of the cost of } \\
\text { equipment) }\end{array}$ & \multicolumn{3}{|l}{} \\
\hline
\end{tabular}

The monetary savings will be calculated as follows:

$$
E_{\text {mon }}=E_{s} \cdot T_{e l}
$$

where $T_{e l}$ - electricity tariff, rub. In the region, the average price of electricity is 4 rubles/kWh.

$E_{\text {mon }}=297675 \cdot 4=1190700 \mathrm{rub}$.

The payback period is estimated as the ratio of total capital investment to savings for the year in monetary terms:

$$
P P=\frac{K}{E_{\text {mon }}}=\frac{2300112}{1190700}=1,9 \text { years }
$$

It is recommended to round off the payback period to whole numbers, i.e., in this case, the payback period is 2 years. The warranty period of the wind turbine is 20 years

Let us summarize the calculation results in a summary table 2.

Table 2. Summary table of the results of the technical and economic calculation.

\begin{tabular}{|c|c|c|c|}
\hline Investments, rub. & $\begin{array}{c}\text { Savings per year, } \\
\text { rub. }\end{array}$ & Operating costs, rub. & Payback period \\
\hline 2300112 & 1190700 & 319168 & $<2$ years \\
\hline
\end{tabular}

\section{Conclusions}

the built mathematical model fully simulate the operation of a wind power plant, which allows to use it for building more complex models, and to assess the economic efficiency of plants of this type;

economic analysis showed that when installing a wind power plant for alternative power supply, capital costs will be 2,300,112 rubles, and the annual energy saving potential from the introduction of a wind turbine in value terms will be 1,190,700 rubles, which pay off this implementation in less than two years;

the results of mathematical modeling showed that the introduction of wind power plants in Russia is a fairly promising and quick-thinking direction, at least from a technological point of view. 


\section{References}

1. J. Whalley, M. Johnson, B. MacMillin. Effect of Turbulence on Savonius Rotor Efficiency / Jeff Whalley // lux review . 2016. URL: http:

//www.me.rochester.edu/courses/ME241.gans/SavoniusRotors(7).pdf/

2. N. H. Mahmoud, EI-Haroun A. A., Wahba E. An experimental study on improvement of Savonius rotor performance [Text] / Mahmoud N. H. // Atlantalightbulbs. 2016.

URL: $\quad / / h t t p: / / a c . e l s-c d n . c o m / S 111001681200049 X / 1-$ s2.0-

S111001681200049X-main.pdf?_tid=f77caf3a- 951f - 11e6-8095-

00000aab0f01\&acdnat=1476787701_e632ae06184035ad9b52d9db13533db3/

3. N. V. Pronin, Model of the wind turbine VEU-3 in the matlab package // Bulletin of the South Ural State University. Series: Energy, No. 37, pp. 143-145, 2018

4. Yu. K. Zholudeva, Maltsev M. V. Mathematical model of the wind generator // Scientific Almanac. No. 4-3 (30). pp. 63 - 67, 2017

5. V. M. Ivanov, Power supply and energy saving with the use of renewable energy sources // Bulletin of SGASU. Urban planning and architecture. No. 2 (19). pp. 88-93, 2015

6. C. Bussar, M. Moos, R. Alvarez, P. Wolf et al, Optimal allocation and capacity of energy storage systems in a future European power system with $100 \%$ renewable energy generation // Energy Procedia, № 46. pp. 40 - 47, 2014

7. W. F. Pickard, A. Q. Shen, N. J. Hansing, Parking the power: Strategies and physical limitations for bulk energy storage in supply demand matching on a grid whose input power is provided by intermittent sources// Renewable and Sustainable Energy Reviews. № 13.pp. 1934- 1945, 2015

8. J. Hossain, A case study of high wind penetration in the Tami 1 Nadu Electricity Utility, ENERGY POLICY, pp. 868-874, 2014

9. V.M. Andreev, A.G. Zabrodsky, S.O. Kognovitsky, Integrated power plant with an energy storage on the basis of the hydrogen cycle // International Scientific Journal for Alternative Energy and Ecology, №2 (46). pp. 99-105, 2017

10. B. V. Lukutin, Muravlev I. O., Plotnikov I. A. Power supply systems with wind and solar power plants. Tomsk: Tomsk Polytechnic Publishing House. University, 120 (2015)

11. B. S. Richards, G. L. Park, T. Pietzsch, A. I. Schafer. Renewable energy powered membrane technology: Brackish water desalination system operated using real wind fluctuations and energy buffering, //Journal of Membrane Science, № 468. p. 224 232, 2014

12. V. V. Elistratov, Wind power plants. Autonomous wind turbines and complexes SPb. : Peter the Great St. Petersburg Polytechnic University, 101 (2018)

13. Bisht, S., Kumar, A., Goyal, N., Ram, M., \& Klochkov, Y. (2021). Analysis of network reliability characteristics and importance of components in a communication network. Mathematics, 9(12) doi:10.3390/math9121347 